\title{
Exergetic Analysis of a New Direct Steam Generation Solar Plant Using Screw Expanders
}

\author{
Paolo Iodice*(D), Giuseppe Langella and Amedeo Amoresano \\ Dipartimento di Ingegneria Industriale, Università degli Studi di Napoli Federico II, 80125 Napoli, Italy; \\ giulange@unina.it (G.L.); amoresan@unina.it (A.A.) \\ * Correspondence: paolo.iodice@unina.it; Tel.: +39-0817683277
}

Received: 12 January 2020; Accepted: 4 February 2020; Published: 7 February 2020

\begin{abstract}
Screw expanders are volumetric machines particularly suitable in energy conversion with steam-liquid mixtures and for the exploitation of low temperature heat sources. This study explored the main criteria to evaluate the thermodynamic advantages and exergetic assessment of an innovative solar electricity generation system: Screw expanders are utilized as power machines and parabolic trough collectors as a thermal source. Such a direct steam generation solar system, which is based on the Rankine cycle, offers benefits in comparison with usual power plants with dynamic expanders: The best exploitation of low temperature heat sources, satisfactory thermal efficiency with steam-liquid mixtures, lower evaporation pressures, and reduced size. Under real working conditions, screw expanders can work at part-load operating conditions; thus, the chief purpose of the present paper was to analyze the exergetic advantages of the planned solar power system when solar radiation and off-design working conditions fluctuate. Initially, the polytropic expansion phase with a specific numerical model is described to evaluate the energy losses that affect the thermodynamic performance of screw expanders when installed in the planned renewable energy power plant. Subsequently, to explore the exergy harnessing in the exhausted steam at off-design working conditions and then to appraise the maximum exergetic efficiency of the proposed screw expander-based solar thermal electricity plant, numerical optimization was performed in a broad range of evaporation and condensation temperatures.
\end{abstract}

Keywords: steam screw expander; part-load behavior; exergetic analysis; polytropic expansion phase

\section{Introduction}

In the last decades, extraordinary consumption of fossil fuels has produced many grave environmental problems all over the world, such as atmospheric pollution and global warming. Nowadays, renewable energy sources characterized by low temperatures and low heat values have received increasing interest owing to their highly accessible amounts for exploitation [1,2]. Besides, in recent years, the need for new metropolitan areas has boosted the development of numerous renewable energy power systems of a compact size, preferring them to a few power systems of greater weight and size.

Being stimulated by such crucial issues, this paper aimed to examine a novel screw expander-based solar thermal electricity plant in which water is used both as the operating fluid and storage. In such a solar electricity generation system (SEGS), which is based on the Rankine cycle, screw expanders (SEs) are utilized as power machines and parabolic trough collectors (PTCs) as a thermal source to produce dry saturated steam. Although power plants adopting screw expanders are at present typically used to exploit low-grade heat recovery applications (such as waste heat recovery and geothermal energy), the proposed direct steam generation (DSG) power plant with screw expanders can also represent an actual and concrete possibility for use in solar electricity generation plants [3-5]. 
Screw expanders, which have attained a high grade of maturity in the last years, can deliver some benefits in comparison with steam turbines, and their field of application differs considerably from those of turbo expanders used in actual SEGSs. The fluid velocities within screw expanders, in fact, are approximately one order of magnitude lower than those in dynamic expanders; thus, the risk of damaging the helical screw rotors (resulting from the admission of steam/liquid blends) is very low. In effect, screw expanders are actually adopted as power machines to convert thermal power to mechanical power under low working pressure, with a simple structure and without reducing the steam Rankine cycle (SRC) efficiency (also admitting two-phase flows) [6-9]. In addition, screw expanders are typically suitable for low-grade heat recovery applications compared to other volumetric power machines $[10,11]$. Considering all these features, screw expanders are a realistic opportunity for DSG power plants in comparison with steam turbines and other sorts of volumetric power machines [5].

That said, little is known about the exergetic assessment of screw expander-based solar thermal electricity plants at part-load operating conditions: The built-in pressure ratios of screw expanders are often much lower than the real expansion ratios in the case of actual solar systems with direct steam generation. Consequently, under these working conditions and adopting a single screw expander, the accessible enthalpy of expansion of high-temperature dry steam cannot be totally exploited $[12,13]$. Hence, to produce mechanical power with satisfactory thermal efficiency under these off-design working conditions, this paper assumed a plant configuration based on two screw expanders joined in series, which are installed in a PTC-based power plant [14,15]

It is very interesting to explore the exergy harnessing in the exhausted steam of the planned DSG solar power system because, under each working condition, a further amount of thermal energy can be converted into an additional rate of electric power that should be delivered to the final consumers. The chief purpose of this analysis was to explain a thermodynamic model of the proposed solar power system to explore the exergetic advantages of DSG solar plants using screw expanders in several working conditions (when fluctuating solar radiation and off-design operating conditions befall). By applying such a mathematical model under part-load working conditions, numerical optimization of all thermodynamic variables was executed to attain maximum exergetic efficiency of the SEGS under examination. Initially, this paper describes the polytropic expansion phase with a specific mathematical model to evaluate all the energy losses that affect the thermodynamic performance of screw expanders when installed in the proposed renewable energy power system. Subsequently, basic principles are established to appraise the exergetic performance of the SE-based DSG solar plant under investigation. Numeric optimization of such a DSG solar system is developed under variable operating conditions by connecting algorithms improved for the planned DSG solar system with thermodynamic model established for the $S E$ at part-load operating conditions.

In such numeric simulations, the evaporation and condensation temperatures of water are optimized with regard to the Rankine cycle efficiency and exergetic efficiency of the whole DSG solar plant with screw expanders. Under a vaporization temperature range between 170 and $300{ }^{\circ} \mathrm{C}$ and condensation pressures ranging between 0.1 and $1 \mathrm{bar}$, numeric optimization is improved by supposing solar radiation that gradually increases from 300 to $900 \mathrm{~W} / \mathrm{m}^{2}$. Therefore, under such fluctuating operating conditions, the optimum evaporation and condensation pressures are calculated in order to maximize the exergetic efficiency of the planned SEGS.

\section{Plant Configuration}

The plant configuration examined in this study was based on two screw expanders joined in series in a solar power system, in which water is utilized as both the working fluid and heat transfer fluid. The schematic plan of such a PTC-SRC power plant is exposed in Figure 1. As power machines, this DSG solar plant adopts two screw expanders $\left(S E_{1}\right.$ and $\left.S E_{2}\right)$ joined in series, while PTCs are adopted as the thermal source [2]. In the PTC-based power plant with DSG under investigation, the expansion process begins in the first screw expander from 3 to $3^{\prime}$ and then the exhaust saturated steam continues to expand into the second $S E$ (from 3' to 4), thus completing the expansion phase. Once the exhausted 
steam is released by the second $S E$, it is condensed by flowing into condenser $C$ (path from 4 to 1 ), thus obtaining saturated liquid, which is then pressurized by pump $P_{1}$ [14]. The saturated steam is thus produced in the PTCs while, afterwards, the dry saturated steam is obtained in the steam separator unit (SS). The flow resistance through the collectors is assumed to have a limited effect on the net power output of the plant because the pressure drop in the PTCs involves a slight increment in the power consumption of pump $P_{1}$ in comparison with the power output of the expander. Hence, the pressure drop in the PTCs is neglected.

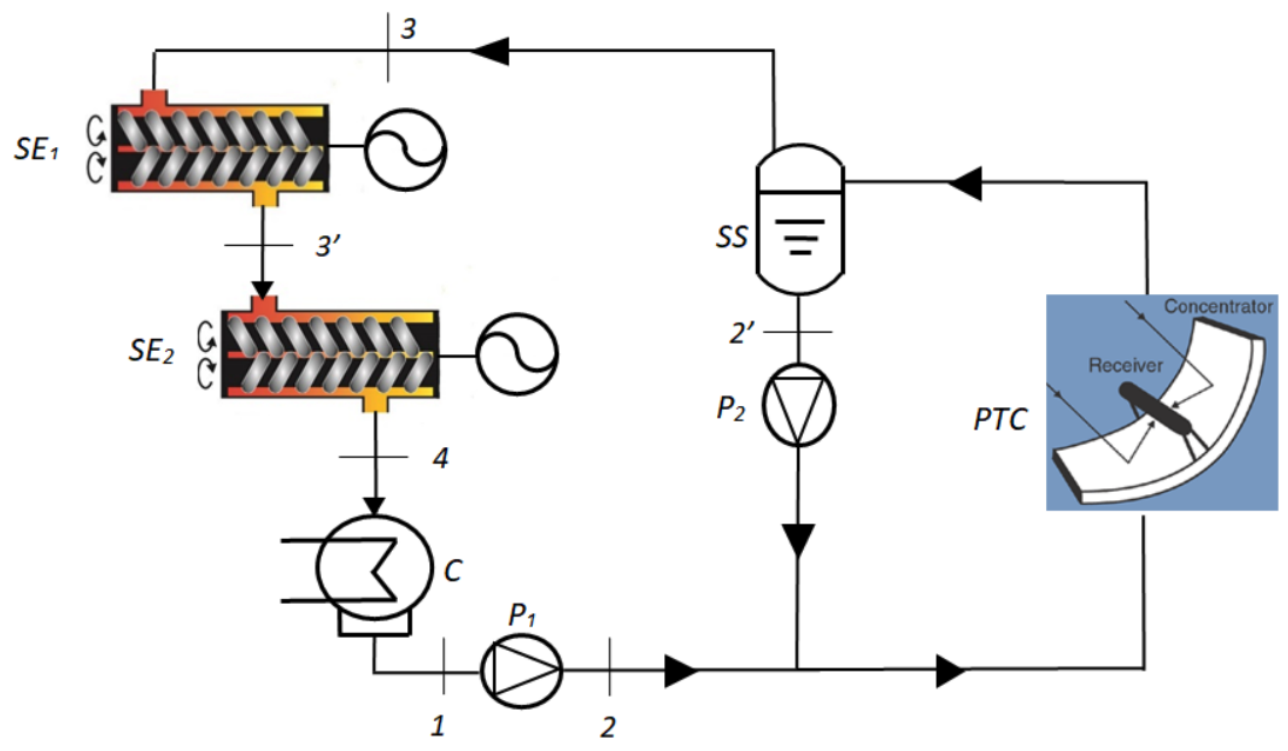

Figure 1. Plant configuration of the PTC-SRC power system.

In the steam Rankine cycle adopted in this study, two screw expanders are assembled in a tandem configuration to completely exploit the whole enthalpy of expansion, which is available from the high-temperature dry saturated steam. Actually, the built-in pressure ratios, $r_{p, b}$, of screw expanders are often much lower than the real expansion ratios, $r_{p}$, of actual solar power plants with direct steam generation. Besides, as it will be better explained in the next paragraph, the overall efficiency of screw expanders progressively drops when the real pressure ratio in actual PTC-SRC power plants increases excessively compared to the settled $S E$ built-in expansion ratio [7]. Consequently, by applying this plant configuration, the entire real pressure ratio can be divided on two screw expanders, so each power machine takes advantage of the lower pressure ratio, also avoiding off-design working conditions.

The numerical simulations performed in the next section will consider several operating conditions for the proposed plant configuration, varying both with the evaporation temperature and the condensation pressure, which will be calculated in order to optimize the exergetic efficiency of the whole PTC-SRC power plant.

\section{Mathematical Models}

\subsection{Solar Energy Collector Efficiency}

In comparison with typical solar electricity generation systems, solar plants that employ parabolic trough collectors are considered as a renowned technology, also for cost abatement [2,16-19]. Really, power plants with direct steam generation based on parabolic trough collectors account for nearly $95 \%$ of the global power provided by real solar power systems all over the world [20-23].

The solar power collector efficiency of a single parabolic trough collector can be assessed by Equation (1):

$$
\eta_{P T C}(T)=0.762-0.212 \cdot \frac{T-T_{a}}{G_{b}}-0.001672 \cdot \frac{\left(T-T_{a}\right)^{2}}{G_{b}} .
$$


In such an equation, $T(\mathrm{~K})$ is the temperature at the inlet of the parabolic trough collector, $T_{a}(\mathrm{~K})$ is the ambient temperature, and $G_{b}\left(\mathrm{~W} / \mathrm{m}^{2}\right)$ is the solar radiation $[16,24]$. In (PTC)-based solar power systems adopting several elementary modules, before water becomes dry saturated steam at the outlet of the parabolic trough collectors, it is both in the binary phase and liquid phase. However, in the liquid phase, in order to achieve a specific outlet temperature of the water, $T_{\text {out }}$, starting from a definite inlet temperature, $T_{i n}$, the needed collector area, $A_{l}$, can be assessed with Equation (2). In such an equation, $C_{p}(T)$ represents the heat capacity in the liquid phase, which is evaluated as in Equation $(3)[25,26]$ :

$$
\begin{aligned}
& A_{l}=\int_{T_{\text {in }}}^{T_{\text {out }}} \frac{\dot{m} \cdot C_{p}(T)}{\eta_{P T C}(T) \cdot G_{b}} d T, \\
& C_{p}(T)=C_{p, 0}+\alpha\left(T-T_{0}\right) .
\end{aligned}
$$

By applying the analytic solution to the formula of integration of Equation (2), if $\Delta h_{l}$ is defined as the increase in enthalpy in the liquid phase region, the solar power collection efficiency, $\eta_{P T C, l}$, in such a phase region can be appraised with Equation (4):

$$
\eta_{P T C, l}=\frac{\dot{m} \cdot \Delta h_{l}}{A_{l} \cdot G_{b}} .
$$

Evidently, the solar power collector efficiency in the binary phase can be estimated by applying Equation (1) since the temperature of the water maintains constant. Therefore, the required collector area, $A_{b}$, in the binary phase can be assessed with Equation (5). In this equation, $\Delta h_{b}$ is defined as the increase in the enthalpy of water in such a phase region and $\dot{m}$ represents the mass flow rate of water flowing into parabolic trough collectors:

$$
A_{b}=\frac{\dot{m} \cdot \Delta h_{b}}{\eta_{P T C, b} \cdot G_{b}} .
$$

For the proposed DSG solar system, the global solar energy collector efficiency is appraised with Equation (6) because the solar field involves the blends of vapor-liquid. In such an equation, $\dot{Q}$ is the heat whole transfer rate in the liquid phase and binary phase:

$$
\eta_{P T C}=\frac{\dot{Q}}{G_{b} \cdot\left(A_{l}+A_{b}\right)}=\frac{\Delta h_{l}+\Delta h_{b}}{\frac{\Delta h_{l}}{\eta_{P T C, l}}+\frac{\Delta h_{b}}{\eta_{P T C, b}} .}
$$

Obviously, the overall solar energy collector efficiency is also appraised with Equation (7), in which $h_{2}$ and $h_{3}$ are the enthalpy levels at the PTC inlet and PTC outlet, respectively, and A is defined as the overall area of the parabolic trough collectors adopted in the DSG solar plant [2,21]:

$$
\eta_{P T C}(T)=\frac{\dot{Q}}{G_{b} \cdot A}=\frac{\dot{m} \cdot\left(h_{3}-h_{2}\right)}{G_{b} \cdot A} .
$$

\subsection{The Isentropic Efficiency of the Screw Expander}

Screw expanders are work-producing devices, which produce mechanical energy by exploiting energy in the operating fluid characterized by high pressure. Such a volumetric machine is defined as a rotary-type positive displacement machine comprising a couple of rotating helical screw rotors. These twin rotors (the male and the female screw rotors) are settled on parallel axes and enclosed in an external casing $[27,28]$. Usually, the working fluid with high enthalpy levels is transferred, at the inlet port, from the chamber of smaller volume toward the chamber of greater size, at the discharge port, without high velocities. In such operating conditions, mechanical power is thus transferred to the shaft that is connected to the generator [29-31]. 
Screw expanders can assure several benefits in comparison with steam turbines. Actually, during the expansion phase, dynamic expanders cannot operate with liquid driblets that can involve severe strains to the helical screw rotors [7]. Contrariwise, screw expanders are rotary power devices characterized by satisfactory efficiency even with the expansion of vapor-liquid blends, from liquid to superheated steam [2]. Really, energy conversion in steam turbines is mostly affected by dynamic effects resulting from high working fluid velocities while, on the other hand, working fluid velocities within the screw expander are significantly lower than those in the dynamic expander. Consequently, the risk of irreparable strains to the rotor blades during the expansion process of liquid-steam mixtures is significantly lower for screw expanders [6,32].

Since SEs can work under part-load operating conditions in many cases when used in direct steam generation solar systems, examining the thermodynamic performance of screw expanders under off-design working conditions (and more, in general, when variable operating conditions befall) is a chief issue for the purposes of this analysis. The screw expander is a volumetric power device, which, under real working conditions, can be considered as a steady flow. Therefore, the expansion phase within the screw expander can be examined with a "black-box" methodology, as already clarified in other scientific publications $[2,7,14]$. The expansion phase within the screw expander can be studied with the isentropic and polytropic processes described in the $p-V$ diagrams of Figure 2.

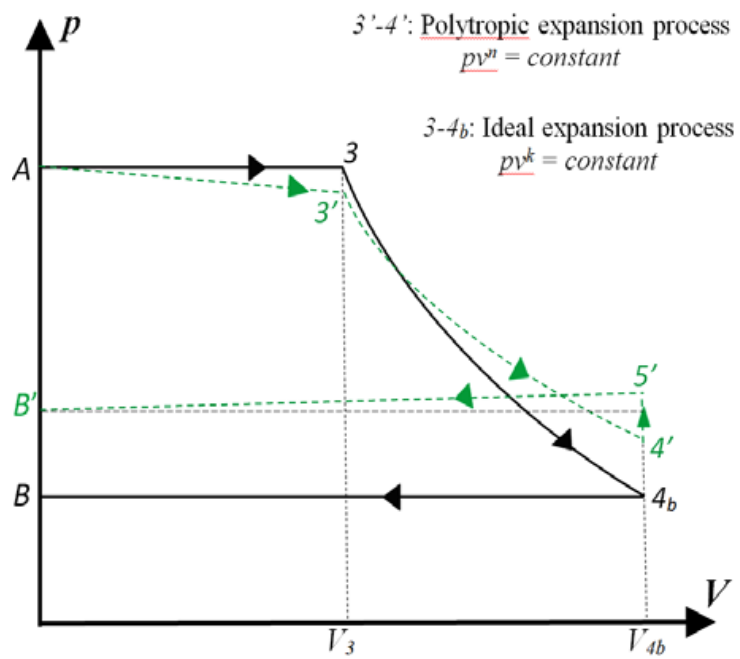

(I): Under-expansion condition $-p_{4}>p_{4 b}$

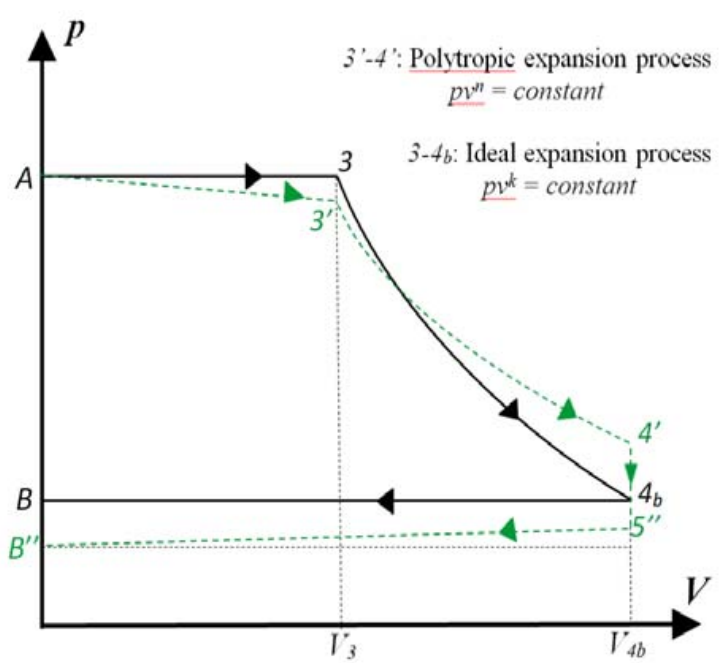

(II): Over-expansion condition $-p_{4}<p_{4 b}$

Figure 2. (I): Real expansion phase with a "blowdown effect" during the polytropic under-expansion process (patch in green line: $A-3^{\prime}-4^{\prime}-5^{\prime}-B^{\prime}$ ) and isentropic expansion process (patch in black line: $A-3-4 b-B)$.(II): Real expansion phase with a "blowback effect" during the polytropic over-expansion process (patch in green line: $\left.A-3^{\prime}-4^{\prime}-5^{\prime \prime}-B^{\prime \prime}\right)$ and isentropic expansion process (patch in black line: $A-3-4 b-B)$.

Several phases can be distinguished during the expansion process $\left(A-3-4_{b}-B\right)$ under ideal isentropic situations. The admission phase at constant pressure, $p_{3}$, which follows the ideal path from $A$ to 3 , the isentropic expansion phase of the fluid that follows the ideal path from 3 to $4_{b}$ (ideal equation $P v^{k}$ $=$ const $)$, and the discharge phase at constant pressure, $p_{4 b}$, that follows the ideal path from $4_{b}$ to $B$. In Figure $2, p_{3}$ is the vaporization pressure and $p_{4 b}$ is the $S E$ built-in discharge pressure of an ideal expansion with $k$ that is relevant the isentropic index.

Nevertheless, some energy losses characterize screw expanders in real operating situations, thereby the following four efficiencies decrease the ideal work output:

- $\eta_{T h}$ is defined as the theoretical efficiency, which contemplates losses caused by ill-matching of the actual pressure ratios, $r_{p}$, to the settled built-in expansion ratio, $r_{p, b}$, of the screw expander [2,7]; 
- $\quad \eta_{L}$ contemplates fluid leakage losses resulting from very skinny clearances between the male and the female screw rotors (smaller than $100 \mu \mathrm{m}$ );

- $\quad \eta_{t i}$ is defined as the thermodynamic efficiency, which characterizes energy losses caused by thermodynamic irreversibility, thus reducing the net work; and

- $\quad \eta_{m}$ represents the mechanical efficiency, which considers losses produced by mechanical frictions from the helical screw rotors.

The overall isentropic efficiency, $\eta_{S E}$, of the screw expander, shown in Equation (8), comprises all the efficiencies itemized overhead, where $\eta_{D}=\eta_{L} \cdot \eta_{t i}$ is defined as the diagram efficiency $[2,3,7]$. Hence, the influence of energy losses caused by the thermodynamic irreversibility on the overall screw expander efficiency, $\eta_{S E}$, are included in the diagram efficiency, $\eta_{D}$ :

$$
\eta_{S E}=\eta_{T h} \cdot \eta_{L} \cdot \eta_{t i} \cdot \eta_{m}=\eta_{T h} \cdot \eta_{D} \cdot \eta_{m}
$$

Such losses can also be appraised by analyzing the state points fixed in the two diagrams of Figure 2. Losses during the admission phase are represented in the real path from $A$ to $3^{\prime}$ (in green line) while losses during the discharge phases are shown in the paths from $5^{\prime}$ to $B^{\prime}$ and from $5^{\prime \prime}$ to $B^{\prime \prime}$ (in green lines). Under real working conditions, losses due to thermodynamic irreversibility can be evaluated in the real expansion phase from 3' to 4'; obviously, these real expansion processes follow the equation $p \cdot v^{n}=$ const, where $n$ is the polytropic index of the working fluid.

Figure 2 also represents losses caused by ill-matching of the actual exhaust pressure, $p_{4}$ (which ranges between $p_{B^{\prime}}$ and $p_{B^{\prime \prime}}$ ), to the fixed discharge pressure of the $S E$ (that is equal to $p_{4 b}$ in an ideal isentropic case and $p_{4^{\prime}}$ in the polytropic expansion process); such mismatching can involve either a "blowback effect" during over-expansion situations (patch from 4 " to 5 ") or a "blowdown effect" during under-expansion situations (patch from $4^{\prime}$ to $5^{\prime}$ ). About this, screw expanders are volumetric power machines with a small built-in volume ratio, $r_{v, b}$; such a parameter is typically set on the basis of the specific screw expander, by considering some characteristics: Rotation speed, geometric shape, and sizes. Usually, a low value for the built-in volume ratio is required in order to completely exploit the available mass flow rate of the operating fluid before the inlet port is shut; therefore, for commercial screw expanders, such a built-in volume ratio, $r_{v, b}$, typically ranges between 2.5 and $6[2,3]$.

Nevertheless, since $r_{p, b}=r_{v, b}{ }^{k}$, a very low built-in volume ratio, $r_{v, b}$, of the screw expander entails a small built-in pressure ratio, thereby causing under-expansion conditions when, under actual operating situations, the operating pressure ratios, $r_{p}$, become higher than the built-in pressure ratio. In these working conditions, the operating fluid will be released at high pressure, thereby decreasing the exploitable energy [10,11].

Under the ideal expansion process, the isentropic work of a steady-flow screw expander is estimated in Figure 1 by the region undergoing the ideal diagram, $p \cdot v^{k}=$ const. Such specific ideal work is defined as the theoretical isentropic work, $W_{T i}$, and it is assessed in Equation (13). Instead, the theoretical diagram work, $W_{T d}$, described in Equation (14) represents the actual work when, in real power systems, the actual pressure ratios deviates from the $S E$ built-in expansion ratio, $r_{p, b}$, then causing off-design working conditions. The pertinent thermodynamic statements are specified in Equations (9)-(12). In Equation (15), $\eta_{T h}$ is defined as the theoretical efficiency and it is calculated by the theoretical isentropic work, $W_{T i}$, and the theoretical diagram work, $W_{T d}$ :

$$
\begin{gathered}
p v^{k}=\text { const }, \\
r_{p}=\frac{p_{3}}{p_{4}}, \\
r_{p, b}=\frac{p_{3}}{p_{4, b}}, \\
r_{v, b}=\frac{v_{4, b}}{v_{3}}=r_{p, b} \eta^{\frac{1}{k}},
\end{gathered}
$$




$$
\begin{gathered}
W_{T i}=-\int_{3}^{4 b} v d p=-\int_{3}^{4 b}[d(p v)-p d v]=p_{3} v_{3}-p_{4 b} v_{4 b}+\int_{3}^{4 b} p d v=\frac{k}{k-1} p_{3} v_{3}\left(1-r_{p}^{\frac{1-k}{k}}\right) \\
W_{T d}=\frac{1}{k-1} p_{3} v_{3}\left(1-\frac{p_{4 b} v_{4 b}}{P_{3} v_{3}}\right)+p_{3} v_{3}-p_{4} v_{4 b}=\frac{1}{k-1} p_{3} v_{3}\left(1-r_{p, b} \eta^{\frac{1-k}{k}}\right)+p_{3} v_{3}\left(1-\frac{r_{p, b}^{\frac{1}{k}}}{r_{p}}\right), \\
\eta_{T h}=\frac{W_{T d}}{W_{T i}}=\frac{\frac{1}{k-1} p_{3} v_{3}\left(1-r_{p, b} \eta^{\frac{1-k}{k}}\right)+p_{3} v_{3}\left(1-\frac{r_{p, b}^{\frac{1}{k}}}{r_{p}}\right)}{\frac{k}{k-1} p_{3} v_{3}\left(1-r_{p}^{\frac{1-k}{k}}\right)}=\frac{\left(1-r_{v, b}^{1-k}\right)+(k-1)\left(1-\frac{r_{v, b}}{r_{p}}\right)}{k\left(1-r_{p}^{\frac{1-k}{k}}\right)}
\end{gathered}
$$

The diagram efficiency, $\eta_{D}$, exposed in Equation (16) is calculated by using the theoretical diagram work, $W_{T d}$ (calculated in Equation (14)), and the thermodynamic work, $W_{T m}$ (which considers both the work for mechanical frictions, $W_{M F}$, and the shaft work output, $\left.W_{S}\right)$. Then, this diagram efficiency, $\eta_{D}$, considers energy losses due to thermodynamic irreversibility and fluid leakage losses [14]. In a previous scientific publication [29], the variation in the diagram efficiency, $\eta_{D}$, with $r_{p}$ and $r_{v, b}$ was exposed when saturated vapor was used as the working fluid. It was shown that the diagram efficiency, $\eta_{D}$, can be reduced by a high built-in volume ratio, but the relevant reductions become insignificant under rising real pressure ratios, $r_{p}$. In effect, when the real expansion ratios are nearly twice the built-in expansion ratio, the values of the diagram efficiency become around constant with the real pressure ratio;

$$
\eta_{D}=\frac{W_{T m}}{W_{T d}}=\frac{W_{S}+W_{M F}}{p_{3} v_{3}\left[\left(\frac{1-r_{v, b} \eta^{1-k}}{k-1}\right)+\left(1-\frac{r_{v, b}}{r_{p}}\right)\right]} .
$$

The overall isentropic efficiency, $\eta_{S E}$, as defined in Equation (8), attains the maximum value, $\eta_{S E, p}$ (peak isentropic efficiency), when the theoretical efficiency, $\eta_{T h}$, attains the maximum value, $\eta_{T h, p}$, as described in Equation (17). By assuming the maximum theoretical efficiency, $\eta_{T h, p}$, to be equal to 1, the overall efficiency of the screw expander is appraised as in Equation (18).

Thus, the peak isentropic efficiency, $\eta_{S E, p}$, comprises fluid leakage losses, losses caused by mechanical frictions, and energy losses resulting from thermodynamic irreversibility. Finally, as explained in Equation (18), once the isentropic index, $k$, the built-in volume ratio, and the peak isentropic efficiency, $\eta_{S E, p}$, are fixed, the overall isentropic efficiency, $\eta_{S E}$, depends on the operating pressure ratio, $r_{p}$ :

$$
\begin{gathered}
\eta_{S E, p}=\eta_{T h, p} \cdot \eta_{D} \cdot \eta_{m} \\
\eta_{S E}=\eta_{S E, p} \cdot \eta_{T h}=\eta_{S E, p} \cdot \frac{\left(1-r_{v, b}^{1-k}\right)+(k-1)\left(1-\frac{r_{v, b}}{r_{p}}\right)}{k\left(1-r_{p}^{\frac{1-k}{k}}\right)} .
\end{gathered}
$$

\subsection{Thermal, Global and Exergetic Efficiency of the PTC-SRC Power System}

In the direct steam generation power system, the power required by the pump and the power delivered by the screw expander are assessed with Equations (19) and (20), respectively. In such equations, $h_{1}$ is the enthalpy value of water at the pump inlet; $\eta_{p}$ is the pump's overall efficiency, which considers both the adiabatic and mechanical efficiency of the pump; and $h_{2, i s}$ is the isentropic enthalpy at the pump outlet, which can be calculated on the basis of the water enthalpy properties by using REFPROP tables once the pressure increase is fixed. Besides, $h_{3}$ is the enthalpy level at the SE inlet and $h_{4, i s}$ is the isentropic enthalpy value at the $S E$ outlet $[6,8]$. All these enthalpy values depend on the specific steam Rankine cycle:

$$
P_{S E}=\dot{m} \cdot\left(h_{3}-h_{4}\right)=\dot{m} \cdot\left(h_{3}-h_{4, i s}\right) \cdot \eta_{S E},
$$




$$
P_{P}=\dot{m} \cdot\left(h_{2}-h_{1}\right)=\dot{m} \cdot\left(h_{2, i s}-h_{1}\right) / \eta_{P}
$$

Therefore, in Equation (21), $\eta_{S R C}$ is the steam Rankine cycle efficiency, where $P_{S R C}$ is the power delivered by the SE-based DSG solar plant and $\dot{Q}$ represents the heat transfer rate of the working fluid:

$$
\eta_{S R C}=\frac{P_{S R C}}{\dot{Q}}=\frac{P_{S E}-P_{P}}{\dot{Q}}=\frac{\left(h_{3}-h_{4, i s}\right) \cdot \eta_{S E}-\left(h_{2, i s}-h_{1}\right) / \eta_{p}}{\left(h_{3}-h_{2}\right)} \text {. }
$$

To appraise the share of solar radiation that can be efficiently converted into net power, $P_{N E T}=$ $P_{S R C} \cdot \eta_{m e c}$, the solar thermal power efficiency, $\eta_{G}$, is introduced in Equation (22), where $\eta_{m e c}$ represents the mechanical efficiency of the whole power plant, also comprising generator efficiency:

$$
\eta_{G}=\frac{P_{N E T}}{G_{b} \cdot A}=\eta_{P T C} \cdot \eta_{S R C} \cdot \eta_{m e c}
$$

To appraise the thermodynamic irreversibility of the renewable energy power system under investigation, the exergetic efficiency, $\eta_{E X}$, is estimated as in Equation (23). In such an equation, $E_{S}$ is the exergy released by solar radiation that can be appraised by using Equation (24), where $T_{0}$ is the reference temperature, $T_{S}$ is the surface temperature of the Sun, and $f$ is defined as the dilution factor [25]. By using Equation (2), such exergetic efficiency is assessed in Equation (25), thus without itemizing a specific value of the mass flow rate, $\dot{m}$, of the working fluid [14]:

$$
\begin{gathered}
\eta_{E X}=\frac{P_{N E T}+\dot{m}\left[\left(h_{4}-h_{1}\right)-T_{0}\left(s_{4}-s_{1}\right)\right]}{E_{S}}=\frac{G_{b} \cdot A \cdot \eta_{G}+\dot{m}\left[\left(h_{4}-h_{1}\right)-T_{0}\left(s_{4}-s_{1}\right)\right]}{E_{S}}, \\
E_{S}=G_{b} \cdot A\left[1-\frac{4 T_{0}}{3 T_{S}}(1-0.28 \ln f)\right] \\
\eta_{E X}=\frac{\eta_{G}+\frac{\eta_{P T C}\left[\left(h_{4}-h_{1}\right)-T_{0}\left(s_{4}-s_{1}\right)\right]}{\left(h_{3}-h_{2}\right)}}{\left[1-\frac{4 T_{0}}{3 T_{S}}(1-0.28 \ln f)\right]}=\frac{\eta_{P T C}\left[\eta_{S R C} \eta_{m e C}+\frac{\left[\left(h_{4}-h_{1}\right)-T_{0}\left(s_{4}-s_{1}\right)\right]}{\left(h_{3}-h_{2}\right)}\right]}{\left[1-\frac{4 T_{0}}{3 T_{S}}(1-0.28 \ln f)\right]} .
\end{gathered}
$$

\section{Results and Discussion}

To evaluate the maximum exergetic efficiency and best working conditions of the planned solar power system under mutable operating conditions, the numerical models described in the previous paragraph were gathered in a computer model comprising a collection of MATLAB subroutines in which thermodynamic properties of water were calculated by using REFPROP tables [14]. Adopting specific thermodynamic simulations based on this computer model, a part-load model on the screw expander was achieved as well as an exergetic appraisal of the whole PTC-SRC power plant when mutable solar radiation and off-design working conditions were encountered.

Initially, the polytropic expansion phase was appraised with over- and under-expansion numerical models to evaluate the energy losses that affect the thermodynamic performance of screw expanders when used in the proposed renewable energy power system, thus revealing variation in the efficiency with the real pressure ratio. Afterwards, numeric optimization of such a solar power plant was developed under several operating conditions by connecting algorithms improved for the planned DSG solar system with the over- and under-expansion models established for the screw expander at part-load operating conditions.

By applying such numeric models, once all the main parameters for the thermodynamic simulations were set (as exposed in Table 1) [2], the evaporation and condensation temperatures of water were optimized with regard to the Rankine cycle efficiency and exergetic efficiency of the whole DSG solar plant adopting screw expanders. For an evaporation temperature range between 170 and $300{ }^{\circ} \mathrm{C}$ and condensation pressures ranging between 0.1 and 1 bar, numeric optimization was improved with increasing solar radiation. 
Table 1. Fixed variables.

\begin{tabular}{cc}
\hline Variables & Fixed Value \\
\hline$T_{a}\left[\mathrm{C}^{\circ}\right]:$ ambient temperature & 25 \\
$\eta_{p}:$ pump efficiency & 0.80 \\
$\eta_{m e c}:$ mechanical efficiency & 0.95 \\
$k:$ isentropic index & 1.13 \\
$\eta_{S E, p}: S E$ peak isentropic efficiency & 0.75 \\
$r_{v, b}: S E$ built-in volume ratio & 5 \\
\hline
\end{tabular}

Using Equation (1), solar power collector efficiencies were calculated, as shown in Figure 3, against the evaporation temperatures, $T_{3}$, under several solar radiations. Such heat collection efficiencies clearly decline with the evaporation temperature, $T_{3}$, for each considered solar radiation [14].

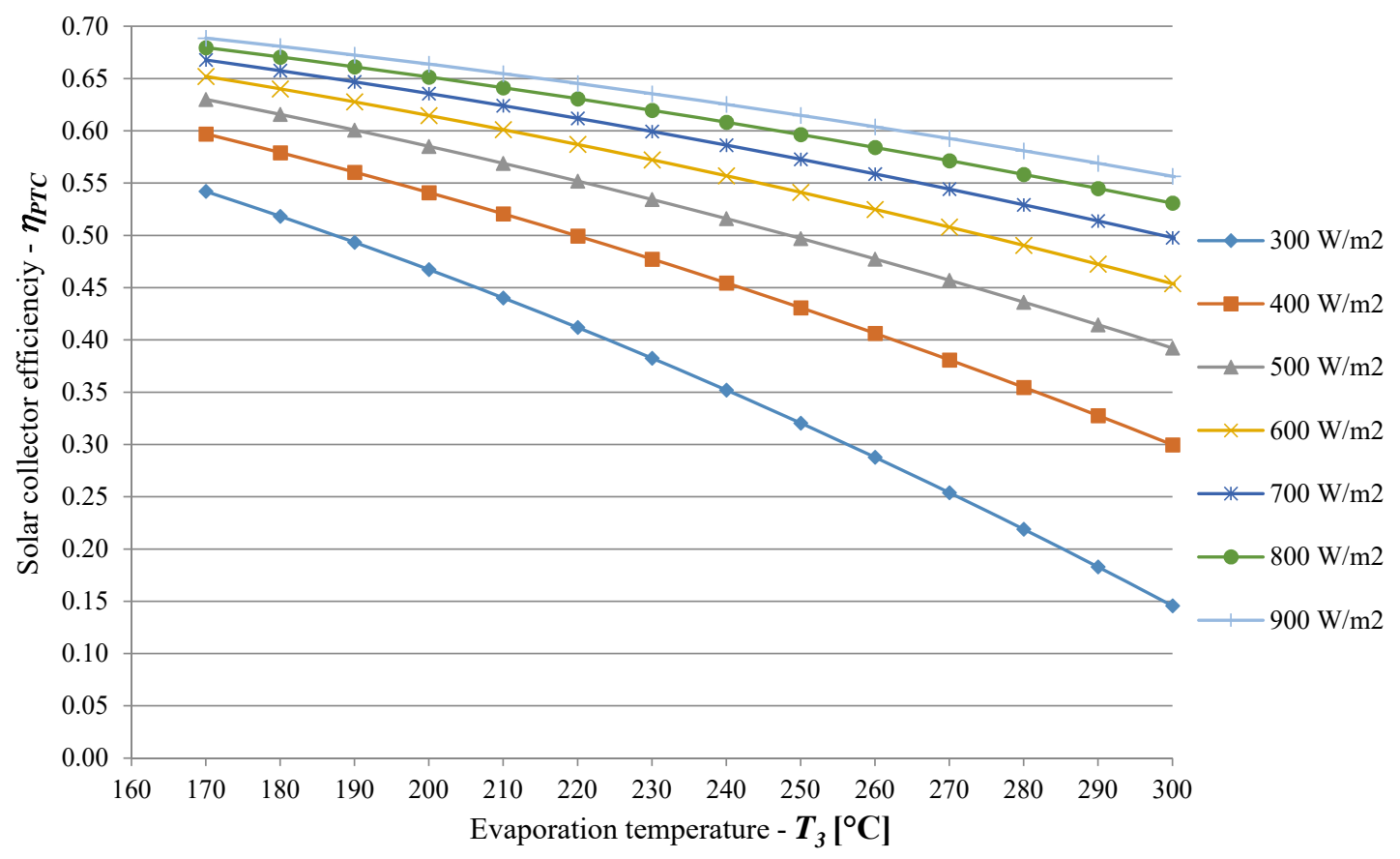

Figure 3. Solar power collection efficiency calculated against the vaporization temperature under rising solar radiation. Reprint with permission [2]; 2020, John Wiley and Sons.

Once the built-in volume ratio was set, by adopting Equation (18), the $S E$ isentropic efficiency, $\eta_{S E}$, was assessed, as shown in Figure 4, against the evaporation temperature under fluctuating condensation pressures. Clearly, an increase in evaporation temperature entails growth in the operating expansion ratio that can result in reduced thermodynamic performance of the screw expanders.

As already explained in the previous paragraph, screw expanders are volumetric power machines with a small built-in volume ratio; such a parameter (previously defined as $r_{v, b}$ ) is typically set on the basis some specific $S E$ characteristics: Rotation speed, geometric shape, and sizes. Usually, a low value for the built-in volume ratio is required in order to completely exploit the available mass flow rate of the operating fluid before the inlet port is shut, thus reducing energy losses due to fluid leakage.

Nevertheless, a very low built-in volume ratio, $r_{v, b}$, of the screw expander entails a small built-in pressure ratio; in effect, $r_{p, b}=r_{v, b}{ }^{k}=6.16$ once $r_{v, b}$ is set to 5 . For this reason, under-expansion operating conditions can befall under real operating situations because the real pressure ratios, $r_{p}$, of the proposed solar power plant become higher than the built-in pressure ratio of the screw expander $\left(r_{p, b}\right)$. In these working conditions, in fact, the operating fluid will be released at high pressure, thereby decreasing the exploitable energy. Besides, as previously explained, while the mismatch of the real pressure ratio, $r_{p}$, with the set built-in pressure ratio can entail blowback and blowdown effects, optimum $S E$ efficiency 
occurs when the operating expansion ratios, $r_{p}$, reach the built-in pressure ratio of the screw expanders $\left(r_{p, b}\right)[14]$.

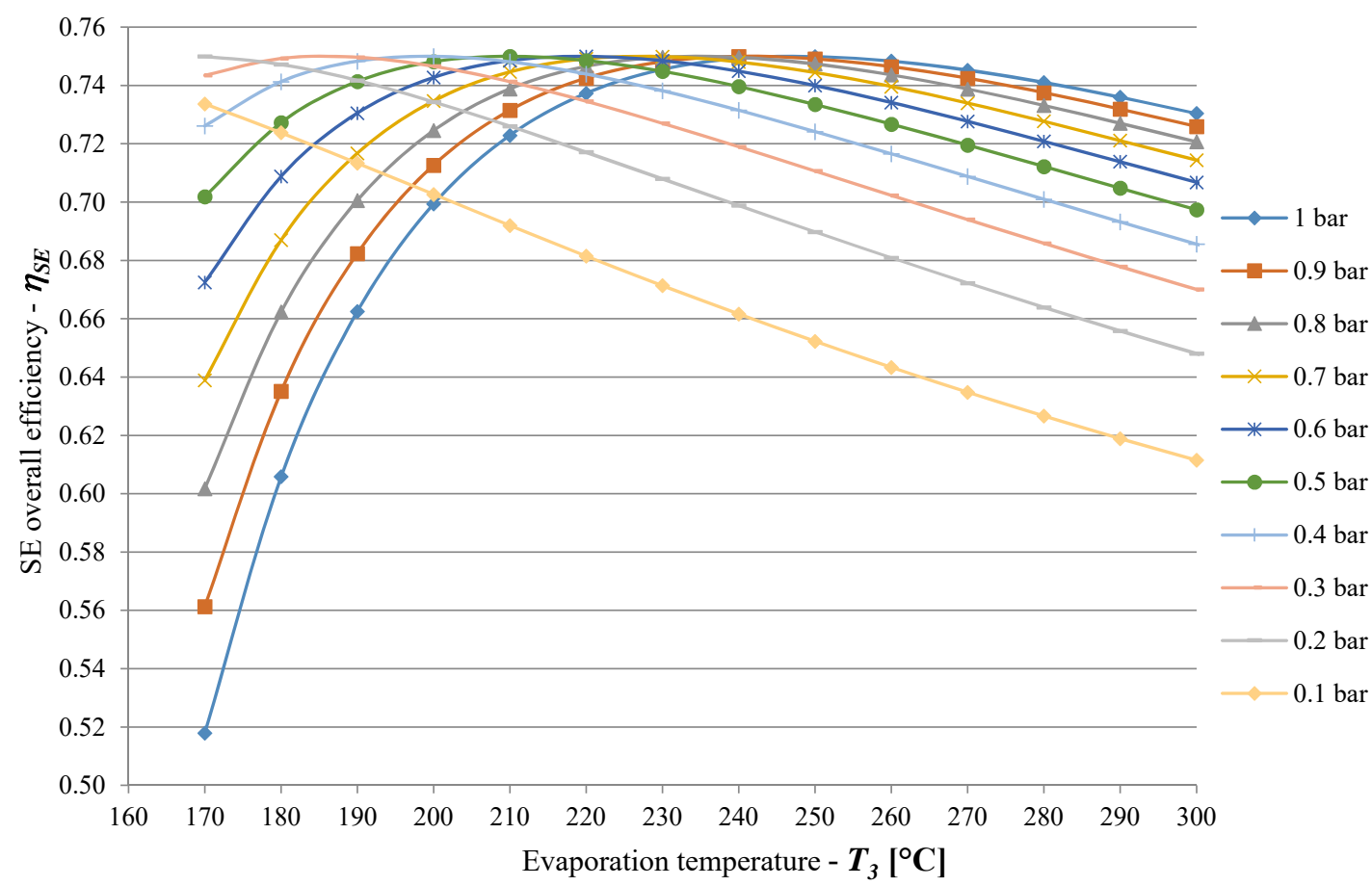

Figure 4. Screw expander overall efficiency calculated against evaporation temperatures and condensation pressures. Reprint with permission [2]; 2020, John Wiley and Sons.

For the solar power system planned in this study, a continuous decrease in $S E$ efficiency, $\eta_{S E}$, is evident in Figure 4 when the evaporation temperature, $T_{3}$, increases and the exhaust pressure, $p_{4}$, decreases. Under such an over-expansion operating condition, in fact, the resulting working expansion ratio increases progressively compared to the set built-in pressure ratio (that is, $r_{p}>r_{p, b}$ ), thus involving the blowback effect [14].

Furthermore, in the same figure, similar off-design working conditions can occur when $r_{p}<r_{p, b}$ (blowdown operating conditions). In such an under-expansion operating condition (the condensation pressures, $p_{4}$, increases and the evaporation temperature, $T_{3}$, declines), in fact, the resulting working expansion ratio decreases gradually compared to the fixed built-in expansion ratio, hence entailing a decrease in the efficiency, $\eta_{S E}$, of the screw expander $[6,9]$.

In Figure 4, it is evident that, for both screw expanders of such a PTC-SRC power plant, optimal operating conditions befall when the condensation pressure, $p_{4}$, exceeds 0.7 bar and the evaporation temperature, $T_{3}$, varies between 240 and $260^{\circ} \mathrm{C}$. For these specific operating conditions, in fact, the corresponding working expansion ratio, $r_{p}$, becomes nearly the same as the built-in pressure ratio, $r_{p, b}[2]$.

Applying Equation (21), the steam Rankine cycle efficiency, $\eta_{S R C}$, is appraised in Figure 5 against the evaporation temperatures and exhaust pressures. Under high condensation pressures and low evaporation temperatures, it is clear that such efficiency is adversely affected both by a decline in the exploitable enthalpy of expansion and a reduction in the efficiency, $\eta_{S E}$, of the screw expander owing to the blowdown effect (under-expansion condition) [2].

On the other hand, such thermal efficiency increases with an increasing vaporization temperature, $T_{3}$, and decreasing condensation pressure, $p_{4}$, because the resulting growth in the exploitable enthalpy of expansion prevails over the reduced performance of the screw expanders due to the over-expansion conditions (blowback effect). However, under very low condensation pressures $\left(p_{4}<0.3\right.$ bar) and high evaporation temperature $\left(T_{3}>280^{\circ} \mathrm{C}\right)$, it is also evident in Figure 5 that the steam Rankine cycle 
efficiency, $\eta_{S R C}$, remains almost constant with an increasing evaporation temperature. Under this specific working condition, in fact, the poor performance of the screw expanders induced by utmost over-expansion conditions (and then by the blowback effect) overcomes the growth in the accessible enthalpy of expansion (as already revealed in Figure 4).

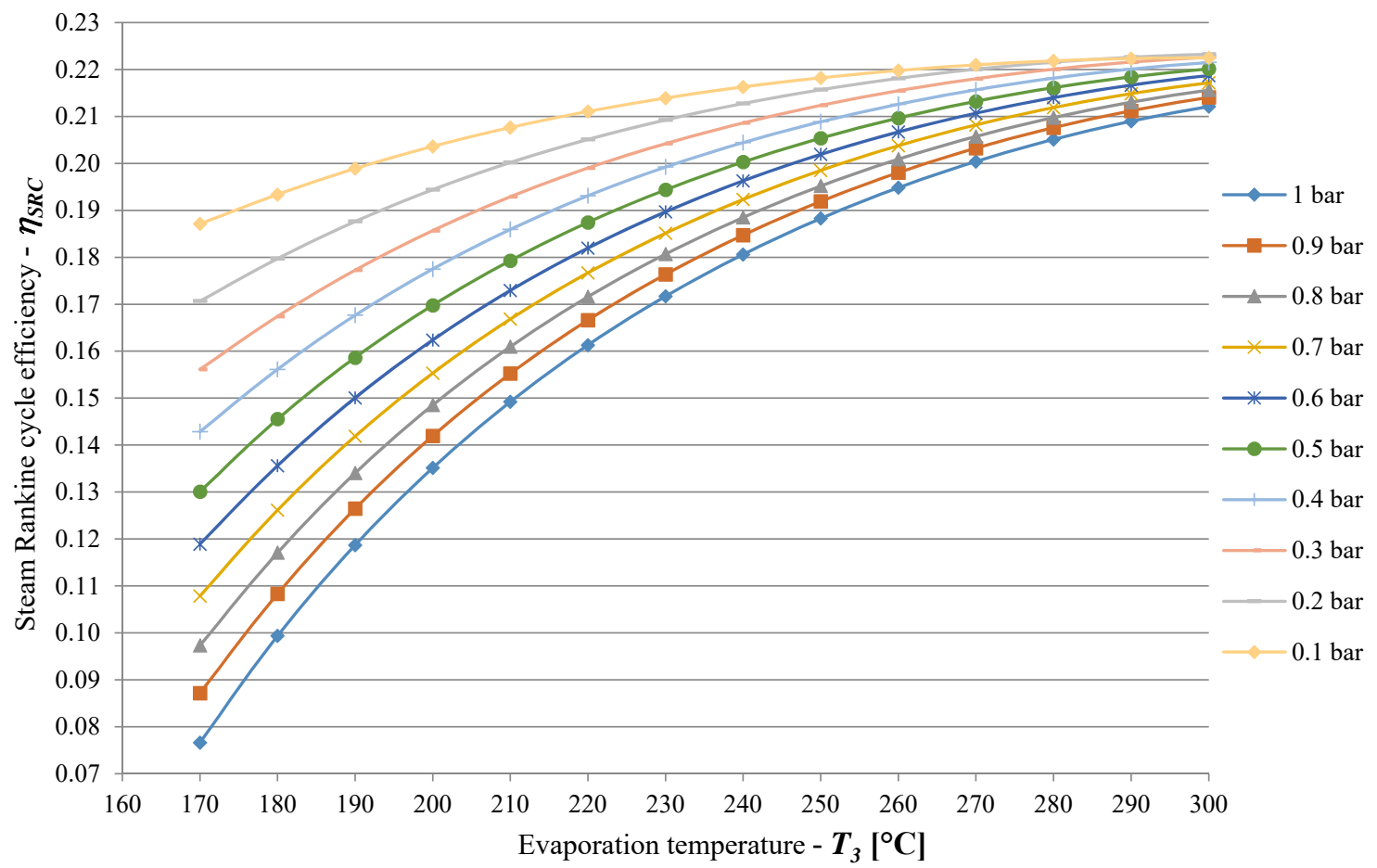

Figure 5. Steam Rankine cycle efficiency calculated against the evaporation temperature under increasing condensation pressure. Reprint with permission [2]; 2020, John Wiley and Sons.

For each plant configuration assumed for the planned DSG solar system, the exergy harnessing in the exhaust working fluid can be exploited by using thermal energy that is available in the condensation heat of the outlet steam. Therefore, under each condensation pressure, such a further amount of thermal energy can be converted into an additional rate of electric power that should be delivered to the final consumers.

To appraise the thermodynamic irreversibility of the DSG power plant under investigation and thus assess the mechanical power exploitable from the outlet steam, the exergetic efficiency, $\eta_{E X}$, can be estimated against the evaporation temperature, $T_{3}$, as in Equation (25). In such an equation, the dilution factor, $f$, is assumed equal to $1.3 \cdot \times 10^{-5}$, the ambient temperature is set as the reference temperature, $T_{0}$, and the surface temperature of the Sun, $T_{S}$, is assumed equal to $5800 \mathrm{~K}$. In this equation, it is clear that such exergetic efficiency, $\eta_{E X}$, depends on the specific steam Rankine cycle, heat collector efficiency, thermal efficiency, $\eta_{S R C}$, and mechanical efficiency, $\eta_{m e c}$, of the whole solar power plant. Therefore, when the built-in volume ratio of the screw expanders is set, the exergetic efficiencies depend on the beam solar radiation, evaporation temperature, $T_{3}$, and condensation pressure, $p_{4}$ [14].

For the SEGS proposed in this paper and in the solar radiation range under investigation (between 300 and $900 \mathrm{~W} / \mathrm{m}^{2}$ ), variations in the exergetic efficiency with the evaporation temperature, $T_{3}$, were estimated, as shown in Figures 6-8, under condensation pressures supposed to be equal to 0.1, 0.4, and 0.7 bar, respectively. 


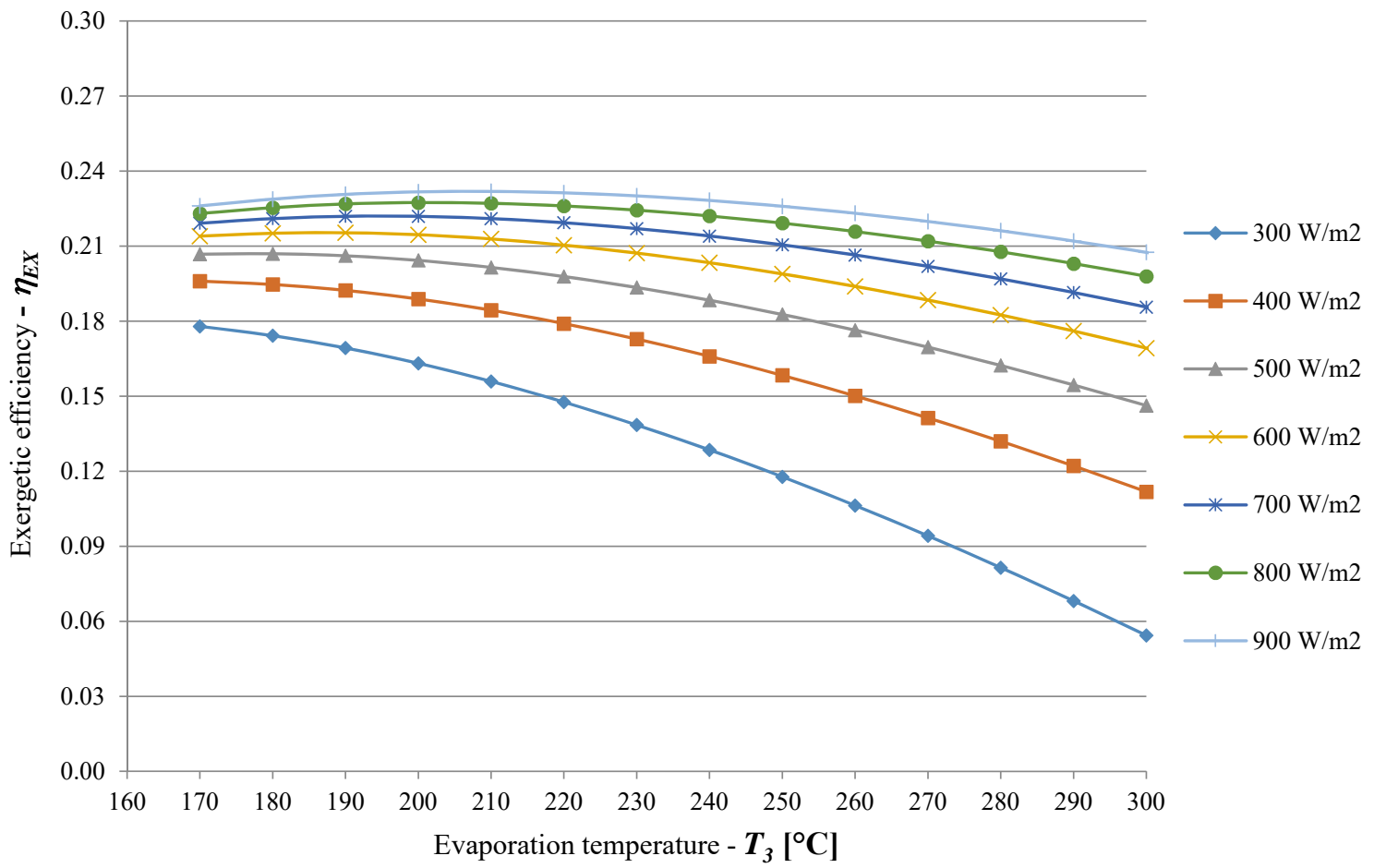

Figure 6. Exergetic efficiency versus vaporization temperature under growing solar radiation when the condensation pressure is fixed at 0.1 bar.

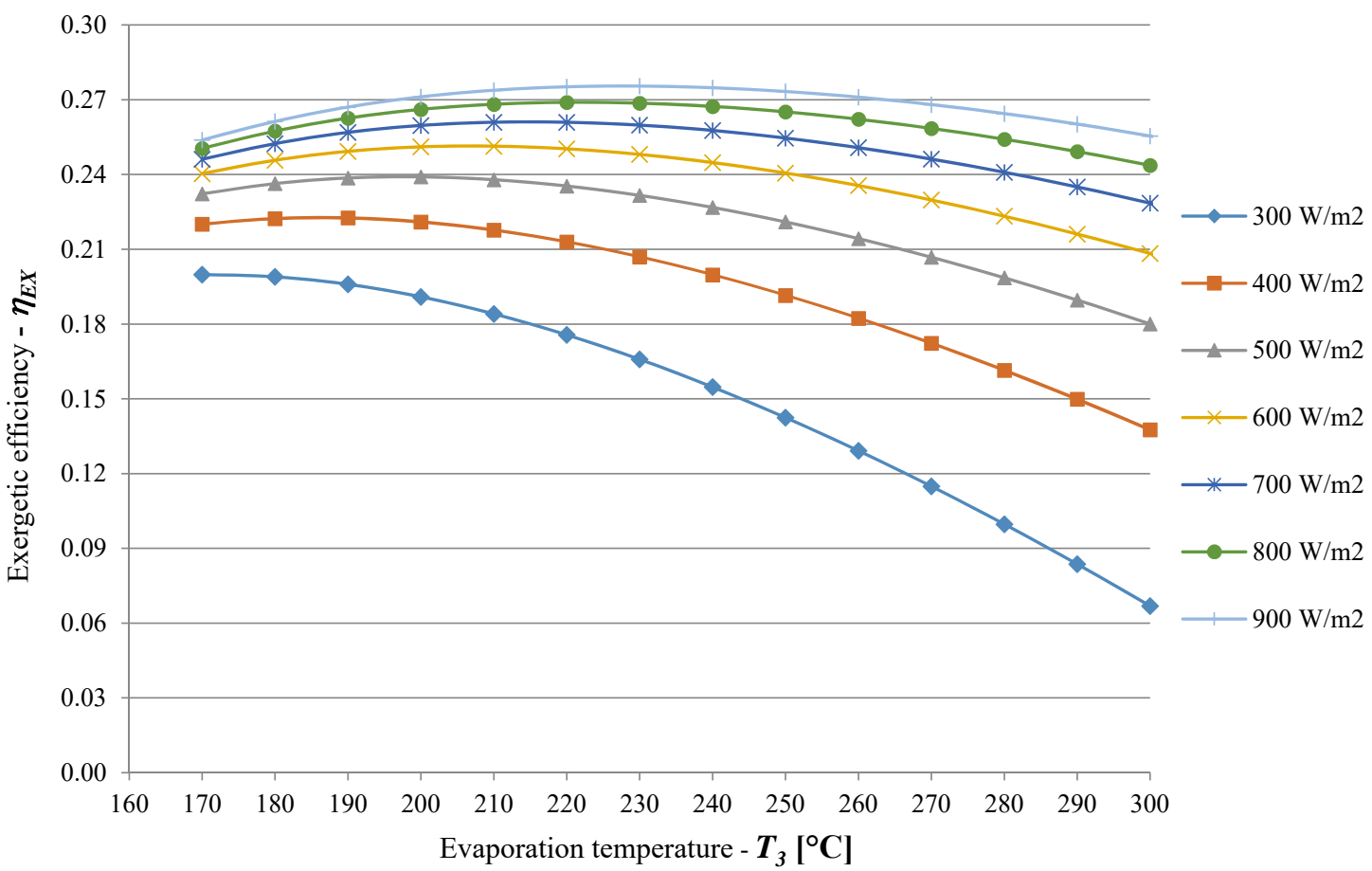

Figure 7. Exergetic efficiency versus vaporization temperature under growing solar radiation when the condensation pressure is fixed at 0.4 bar. 


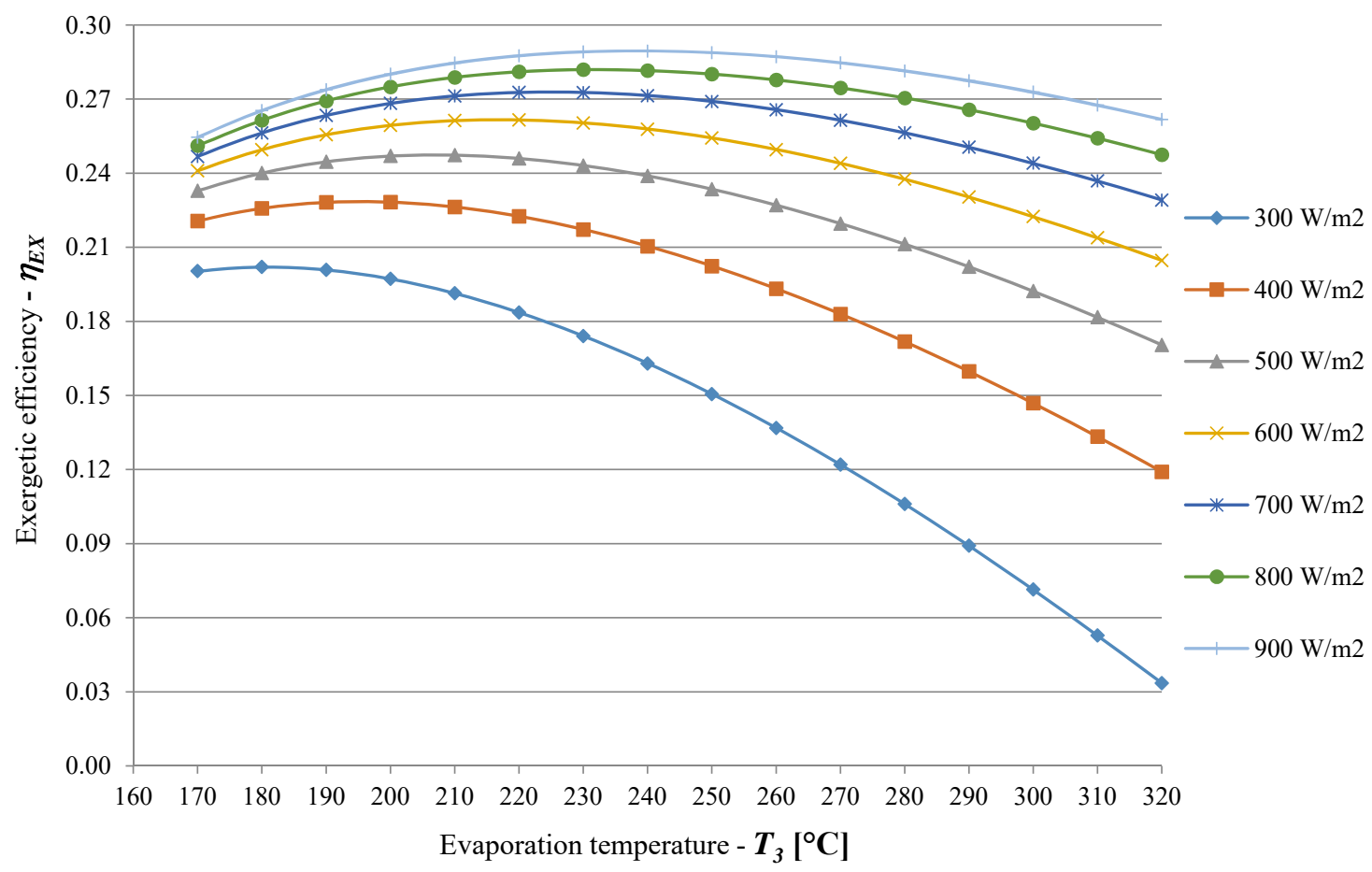

Figure 8. Exergetic efficiency versus vaporization temperature under growing solar radiation when the condensation pressure is fixed at 0.7 bar.

For thee condensation pressure set at 0.1 bar, Figure 6 clearly displays that small vaporization temperatures induce a little lower or nearly constant exergetic efficiencies, $\eta_{E X}$, for each solar radiation in comparison with its maximum values, as shown in Figure 5 from the trend of the steam Rankine cycle under the same exhaust pressure. Instead, for each condensation pressure and for high evaporation temperatures, $T_{3}$ (so in over-expansion working conditions), the exergetic efficiency, $\eta_{E X}$, always drops with an increasing temperature, $T_{3}$, because reductions in the condensation heat and collector efficiency with an increasing vaporization temperature prevail over rises in the accessible enthalpy of the expansion and steam Rankine cycle efficiency.

In order to better comprise all these results, for the same solar radiation range and plant configuration under examination, variations in exergetic efficiency were also calculated against the exhaust pressure, as shown in Figures 9-11, for an evaporation temperature assumed to be equal to 170,230 , and $300{ }^{\circ} \mathrm{C}$, respectively. When the evaporation temperature is fixed at 230 and $300{ }^{\circ} \mathrm{C}$, for each solar radiation, the maximum exergetic efficiencies, $\eta_{E X}$, occur under a condensation pressure, $p_{4}$, fixed to 1 bar, as shown in Figures 10 and 11. In these two figures, in effect, the exergetic efficiency is always a growing function of the exhaust pressure, $p_{4}$; such a circumstance occurs because a rise in the condensation pressure involves a rise in the condensation heat (which is able to be harnessed from the outlet steam), which exceeds the resulting reduction in the thermal efficiency, $\eta_{S R C}$. Besides, by numerical simulations, these particular working conditions were verified for each evaporation temperature higher than $180^{\circ} \mathrm{C}$.

Successively, in order to discover the optimum working conditions of the proposed renewable energy power system with respect to the exergetic efficiency in a broad range of fluctuating evaporation and condensation pressures, mathematical functions indicating variations in the exergetic efficiency with the evaporation temperature and solar radiation were calculated under each exhaust pressure, $p_{4}$, between 0.1 and 1 bar. For the purpose of this numeric optimization, the first derivative of such mathematical functions was set to zero $\left(d \eta_{E X} / d T_{3}=0\right)$ by including in the computer model a specific MATLAB subroutine [14]. Adopting such a calculation process, variations in the optimal vaporization temperature, $T_{3, o p}$, were assessed with solar radiations and condensation pressures, as exposed in 
Figure 12. Thus, in Figure 13, by using such optimal evaporation temperatures, $\mathrm{T}_{3,0 p}$, the resulting optimal exergetic efficiency, $\eta_{E X, o p}$, was assessed with solar radiations and condensation pressures.

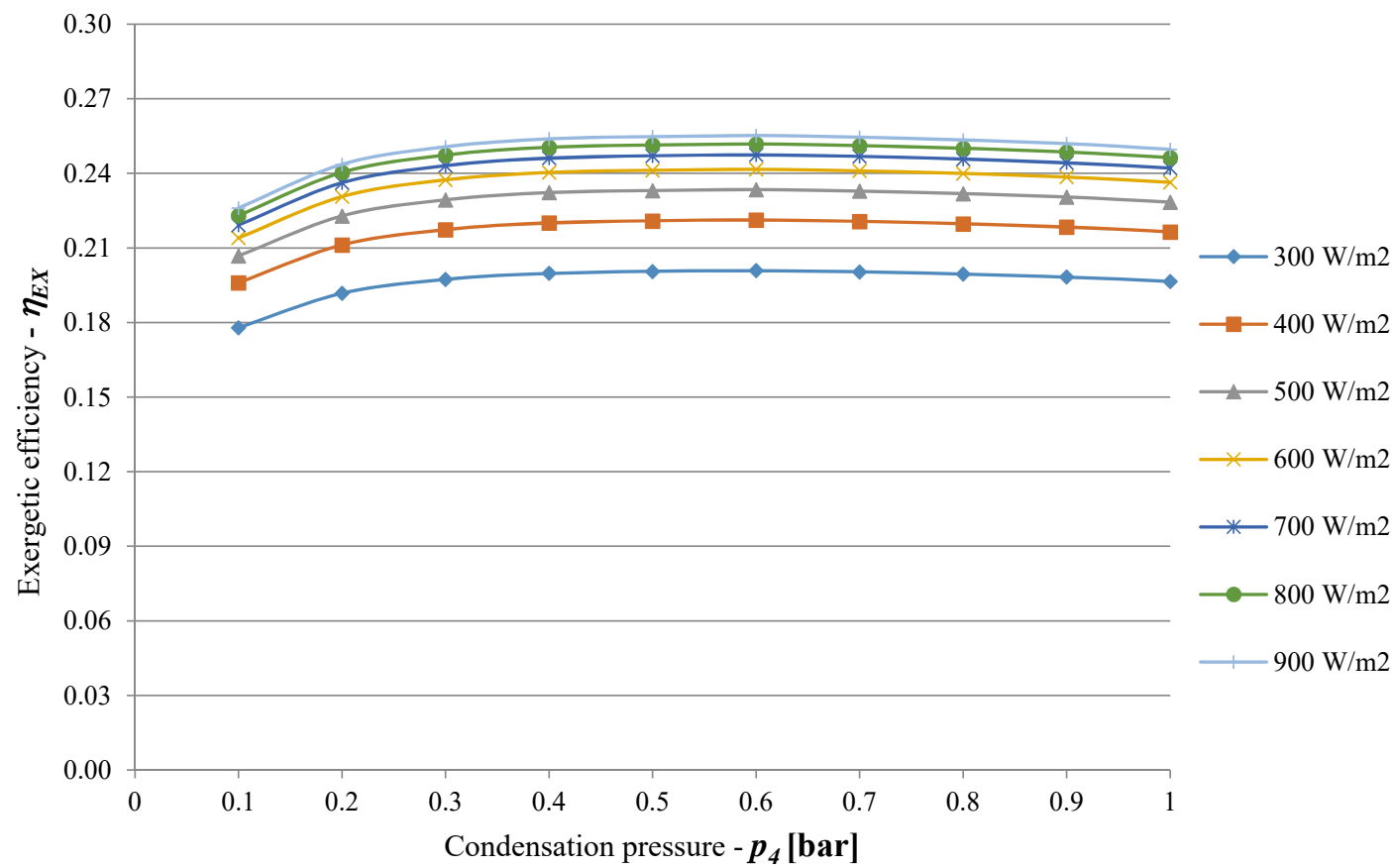

Figure 9. Exergetic efficiency versus condensation pressure under increasing solar radiations when the evaporation temperature is set at $170{ }^{\circ} \mathrm{C}$.

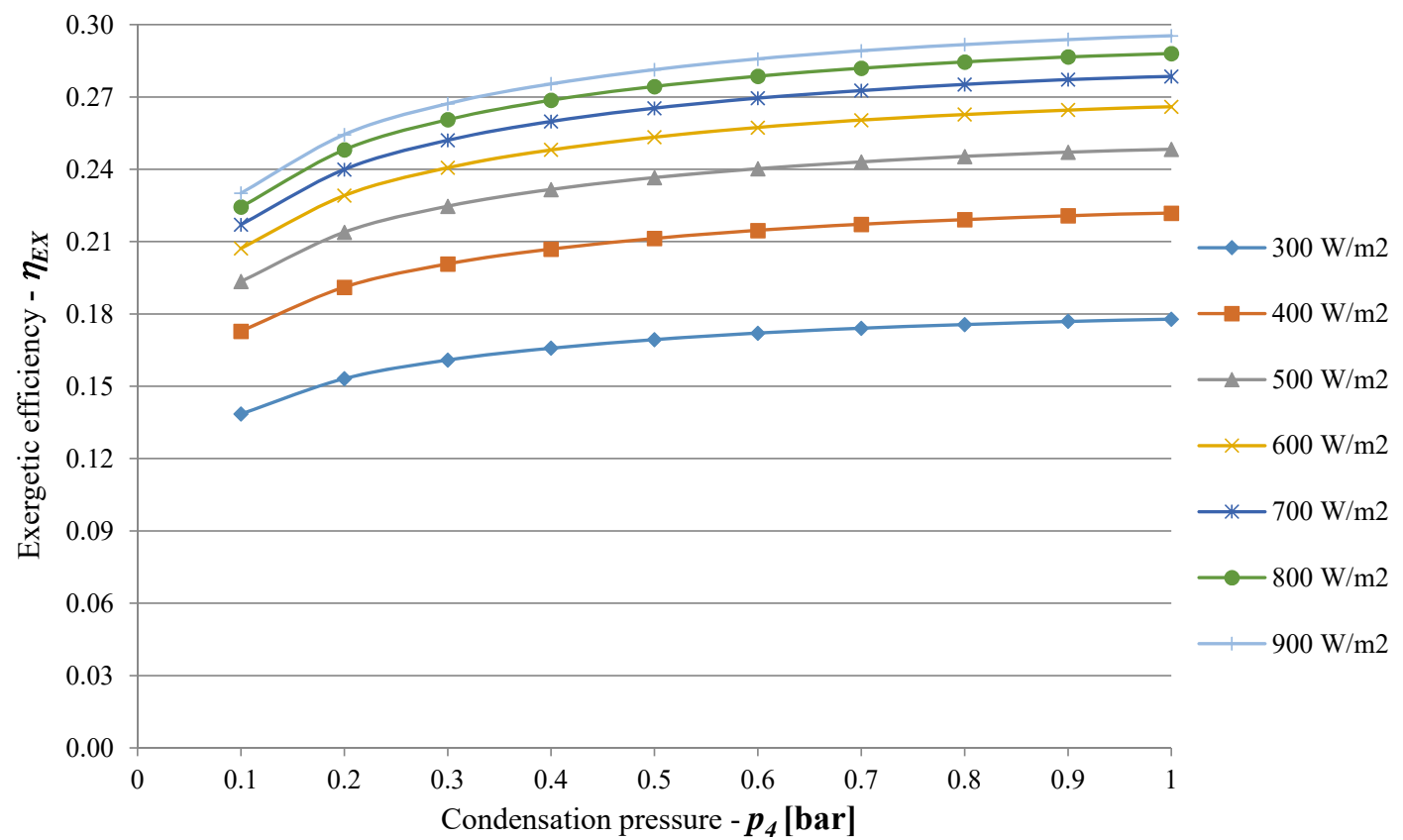

Figure 10. Exergetic efficiency versus condensation pressure under increasing solar radiations when the evaporation temperature is set at $230{ }^{\circ} \mathrm{C}$.

In Figure 12, it is clear that, under each solar radiation, the optimum evaporation temperatures always rise with growing condensation pressures between 0.1 bar and 1 bar. In Figure 13, under solar radiation higher than $300 \mathrm{~W} / \mathrm{m}^{2}$, and the optimal exergetic efficiencies are a monotonically increasing function of the growing exhaust pressure. In this regard, as already explained, the best exergetic 
efficiencies always occur when the condensation pressure is fixed to 1 bar for each solar radiation, thus decreasing the thermodynamic irreversibility of the proposed solar power plant.

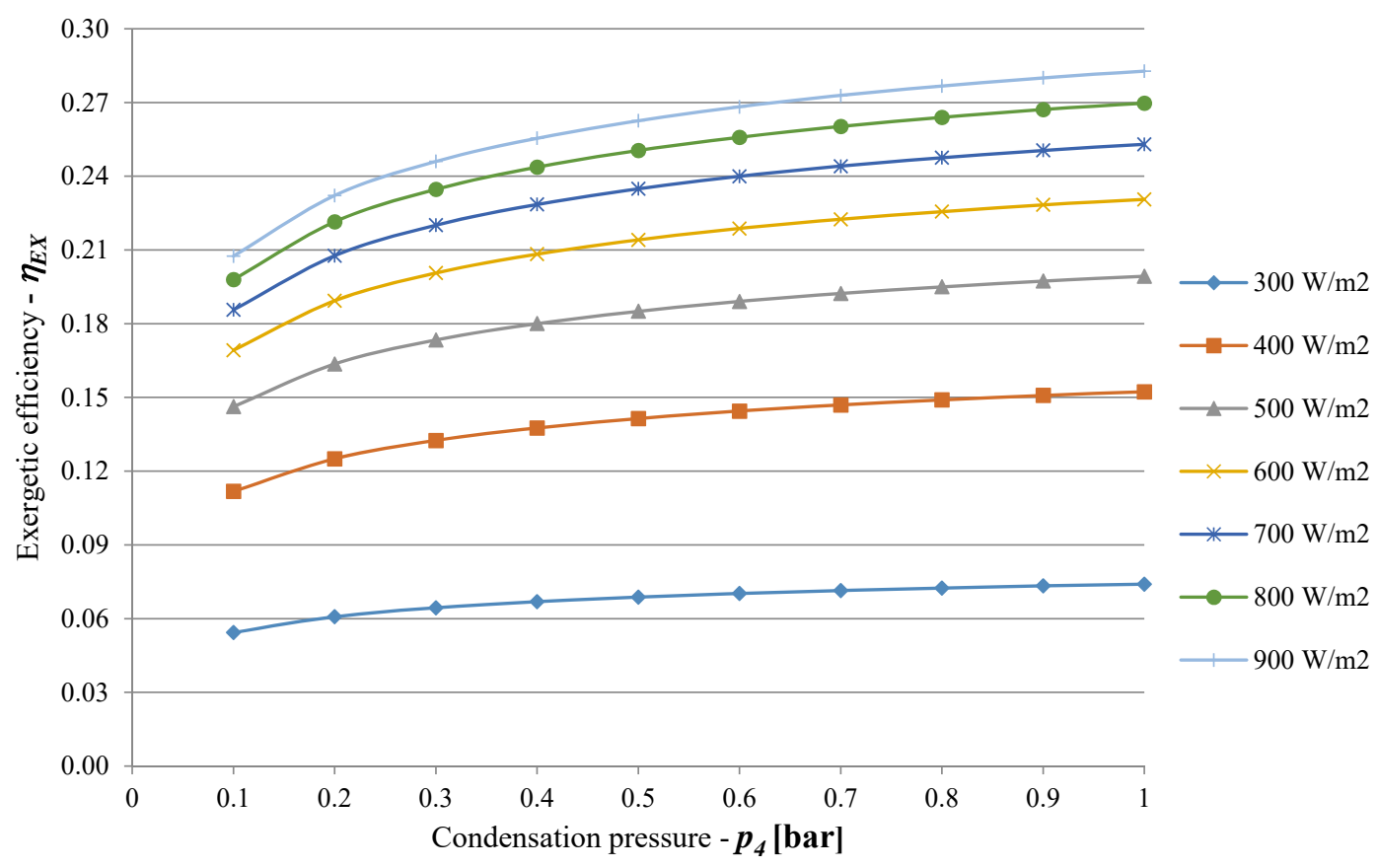

Figure 11. Exergetic efficiency versus condensation pressure under increasing solar radiations when the evaporation temperature is set at $300{ }^{\circ} \mathrm{C}$.

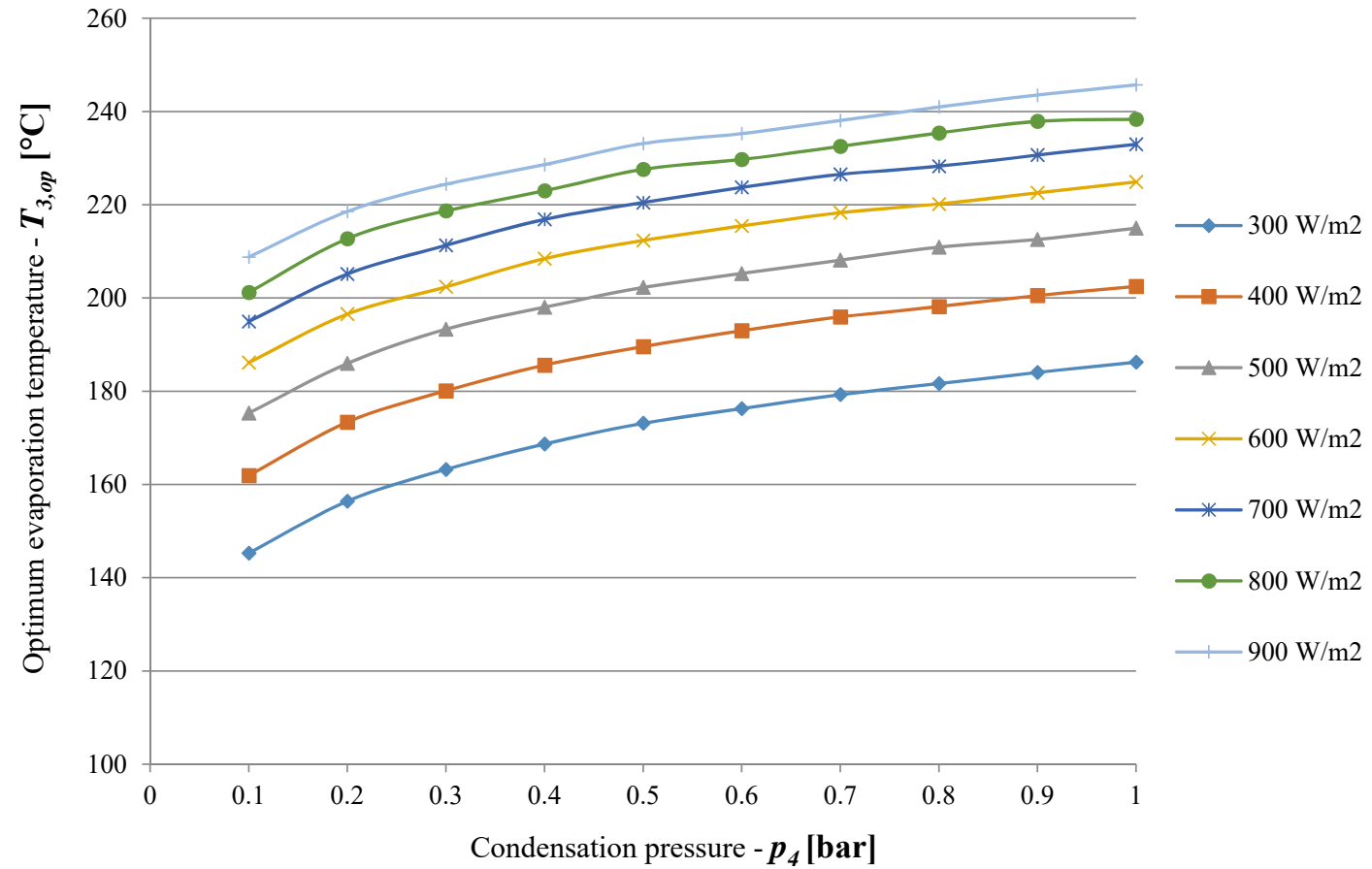

Figure 12. Optimal evaporation temperatures versus solar radiation and condensation pressure. 


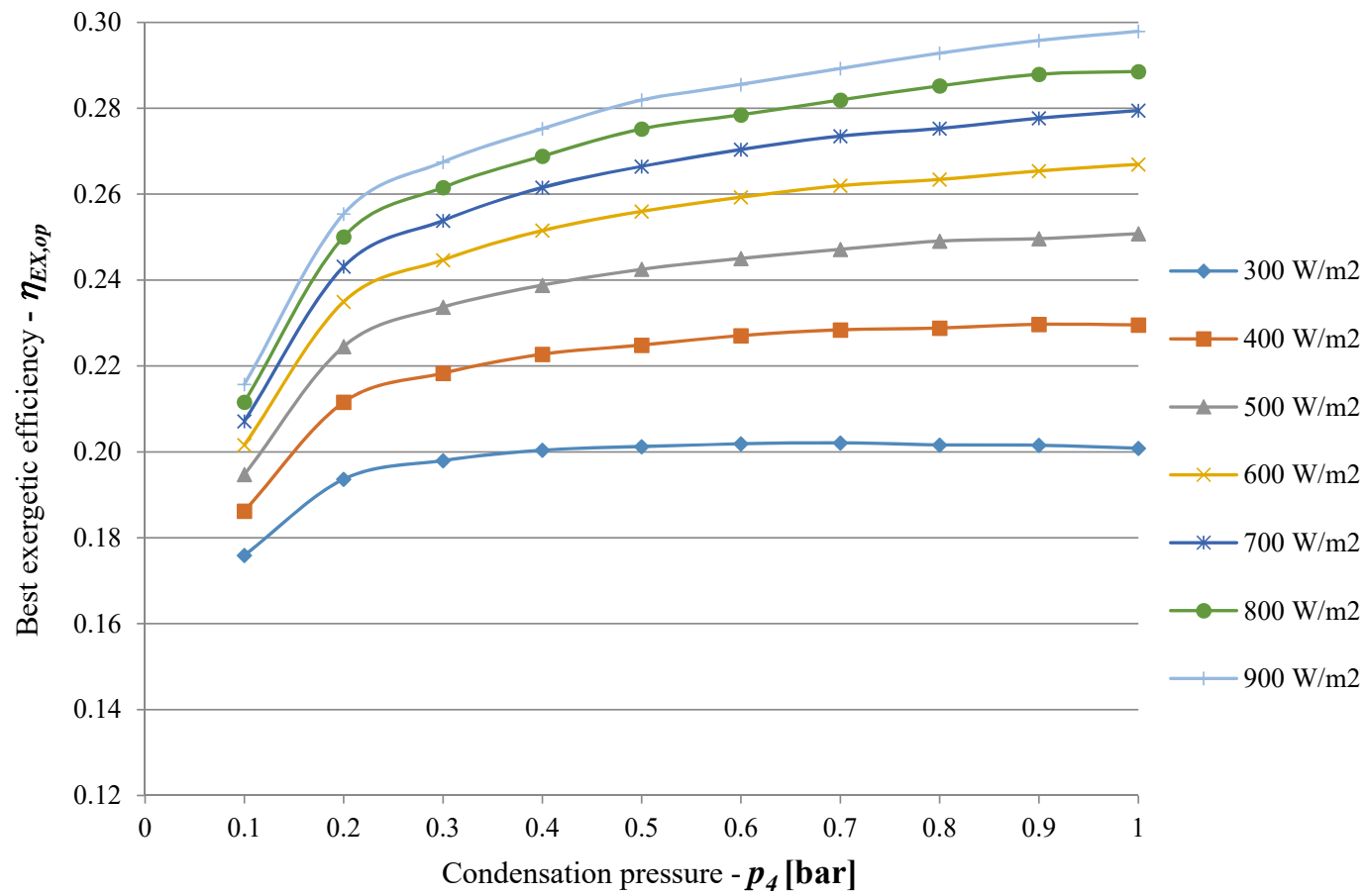

Figure 13. Optimal exergetic efficiencies versus solar radiation and condensation pressure.

The results reported in Figure 12 indicate that, under the detected best operating conditions with respect to the exergetic efficiency (condensation pressure equal to 1 bar), optimal vaporization temperatures increase from around 186 to $246^{\circ} \mathrm{C}$ with rising solar radiation. Under such particular operating conditions, as a result, the maximum exergetic efficiencies, $\eta_{E X, o p}$, rise from around $20.1 \%$ to $29.8 \%$ under increasing solar radiation, as shown in Figure 13. The optimal evaporation temperatures and exergetic efficiencies of the proposed PTC-SRC system are also reported in Table 2 when the condensation pressure was fixed at 1 bar and for the whole solar radiation range under investigation.

Table 2. Optimal evaporation temperatures and exergetic efficiencies of the PTC-SRC system when condensation pressure is fixed at 1 bar.

\begin{tabular}{ccc}
\hline Solar Radiation $\left[\mathbf{W} / \mathbf{m}^{2}\right]$ & $\begin{array}{c}\text { Optimum Evaporation } \\
\text { Temperature } \mathbf{T}_{\mathbf{3}, \boldsymbol{o} \boldsymbol{p}}\left[\mathbf{C}^{\circ}\right]\end{array}$ & $\begin{array}{c}\text { Optimum Exergetic Efficiency } \\
\eta_{\text {EX, } \boldsymbol{o} \boldsymbol{p}}\end{array}$ \\
\hline 300 & 186.2 & 0.201 \\
400 & 202.5 & 0.229 \\
500 & 215.0 & 0.251 \\
600 & 224.9 & 0.267 \\
700 & 233.0 & 0.279 \\
800 & 238.3 & 0.289 \\
900 & 245.7 & 0.298 \\
\hline
\end{tabular}

\section{Conclusions}

Screw expanders are volumetric machines particularly suitable in energy conversion with steam-liquid mixtures and for the exploitation of low temperature heat sources. The PTC-SRC power plants based on steam SEs offer several advantages regarding the low evaporation pressure, low technical requisites, and reduced size. In the renewable energy power plant analyzed in this study, parabolic trough collectors were used as a thermal source and two screw expanders (in a tandem configuration) as power machines. In such a solar power plant, the exergy harnessing in the exhaust working fluid is exploited by using thermal energy that is available in the condensation heat of the outlet steam. To appraise the maximum exergetic efficiency and optimum working conditions of this 
PTC-SRC system at off-design working conditions, numerical optimization was performed in a broad range of fluctuating evaporation and condensation pressures.

The chief results obtained in this study on the thermodynamic performance of this particular kind of SEGS can be shortened as follows:

- The optimal operating conditions of screw expanders befall when the condensation pressure exceeds 0.7 bar and the vaporization temperature varies between 240 and $260^{\circ} \mathrm{C}$. For these specific operating conditions, in fact, the corresponding working expansion ratios become nearly the same as the $S E$ built-in pressure ratio.

- Under high condensation pressures and low evaporation temperatures, the Rankine cycle efficiency is adversely affected both by a decline in the exploitable enthalpy of expansion and a drop in the isentropic efficiency of the screw expander owing to the blowdown effect.

- The Rankine cycle efficiency increases with an increasing vaporization temperature and decreasing condensation pressure because the resulting growth in the exploitable enthalpy of expansion prevails over the reduced performance of the screw expanders due to the blowback effect.

- The optimal exergetic efficiencies are a monotonically increasing function of the growing exhaust pressure because a rise in condensation heat (harnessing in the condenser of the solar power plant) with growing condensation pressure equipoises the resulting reduction in the thermal efficiency.

- Under the best operating condition with respect to the exergetic efficiency (that is, condensation pressure equal to 1 bar), the optimal vaporization temperatures increase from around 186 to $245{ }^{\circ} \mathrm{C}$ with rising solar radiation. As a result, the corresponding maximum exergetic efficiencies rise from around $20.0 \%$ to $29.8 \%$ with rising solar radiation.

Author Contributions: Contributions of P.I.: Data curation, Methodology, Software, Writing-original draft, Writing-review \& editing. Contributions of G.L.: Data curation, Writing-review \& editing, Validation. Contributions of A.A.: Data curation, Software, Supervision. All authors have read and agreed to the published version of the manuscript.

Funding: This research received no external funding.

Conflicts of Interest: The authors declare no conflict of interest.

\section{References}

1. Avadhanula, V.K.; Lin, C.S. Empirical models for a screw expander based on experimental data from organic Rankine cycle system testing. J. Eng. Gas Turbines Power 2014, 136, 062601. [CrossRef]

2. Iodice, P.; Langella, G.; Amoresano, A. Energy performance and numerical optimization of a screw expander-based solar thermal electricity system in a wide range of fluctuating operating conditions. Int. J. Energy Res. 2019, 1-17. [CrossRef]

3. Zhu, Y.; Jiang, L.; Jin, V.; Yu, L. Impact of built-in and actual expansion ratio difference of expander on ORC system performance. Appl. Therm. Eng. 2014, 71, 548-558. [CrossRef]

4. Smith, I.K.; Stosic, N.; Kovacevic, A. Power Recovery from Low Grade Heat by Means of Screw Expanders; Chandos Publishing-Elsevier: Amsterdam, The Netherlands, 2014.

5. Fatigati, F.; Di Bartolomeo, M.; Cipollone, R. Dual intake rotary vane expander rechnology: Experimental and theoretical assesment. Energy Convers. Manag. 2019, 186, 156-167. [CrossRef]

6. Li, J.; Li, P.; Pei, G.; Alvi, J.Z.; Ji, J. Analysis of a novel solar electricity generation system using cascade Rankine cycle and steam screw expander. Appl. Energy 2016, 165, 627-638. [CrossRef]

7. Li, J.; Li, P.; Gao, G.; Pei, G.; Su, Y.; Ji, J. Thermodynamic and economic investigation of a screw expander-based direct steam generation solar cascade Rankine cycle system using water as thermal storage fluid. Appl. Energy 2017, 195, 137-151. [CrossRef]

8. Read, M.; Stosic, N.; Smith, I.K. Optimization of screw expanders for power recovery from low-grade heat sources. Energy Technol. Policy 2014, 1, 131-142. [CrossRef] 
9. Invernizzi, C.; Iora, P.; Silva, P. Bottoming micro-Rankine cycles for micro-gas turbines. Appl. Therm. Eng. 2007, 27, 100-110. [CrossRef]

10. Li, P.; Li, J.; Gao, G.; Pei, G.; Su, Y.; Ji, J.; Ye, B. Modeling and optimization of solar-powered cascade Rankine cycle system with respect to the characteristics of steam screw expander. Renew. Energy 2017, 112, 398-412. [CrossRef]

11. Smith, I.K.; Stosic, N.; Kovacevic, A. Screw expanders increase output and decrease the cost of geothermal binary power plant systems. Trans. Geotherm Resour. 2005, 29, 787-794.

12. Papes, I.; Degroote, J.; Vierendeels, J. New insights in twin screw expander performance for small scale ORC systems from 3D CFD analysis. Appl. Therm. Eng. 2015, 91, 535-546. [CrossRef]

13. Tian, Y.; Xing, Z.; He, Z.; Wu, H. Modeling and performance analysis of twin-screw steam expander under fluctuating operating conditions in steam pipeline pressure energy recovery applications. Energy 2017, 141, 692-701. [CrossRef]

14. Iodice, P.; Langella, G.; Amoresano, A. Modeling and energetic-exergetic evaluation of a novel screw expander based direct steam generation solar system. Appl. Therm. Eng. 2019, 155, 82-95. [CrossRef]

15. Li, P.; Li, J.; Tan, R.; Wang, Y.; Pei, G.; Jiang, B.; Tang, J. Thermo-economic evaluation of an innovative direct steam generation solar power system using screw expanders in a tandem configuration. Appl. Therm. Eng. 2019, 148, 1007-1017. [CrossRef]

16. Li, L.; Sun, J.; Li, Y.; He, Y.L.; Xu, H. Transient characteristics of a parabolic trough direct-steam-generation process. Renew. Energy 2019, 135, 800-810. [CrossRef]

17. Li, L.; Sun, J.; Li, Y. Thermal load and bending analysis of heat collection element of direct-steam-generation parabolic-trough solar power plant. Appl. Therm. Eng. 2017, 127, 1530-1542. [CrossRef]

18. Price, H.; Lupfert, E.; Kearney, D.; Zarza, E.; Cohen, G.; Gee, R.; Mahoney, R. Advances in parabolic trough solar power technology. J. Sol. Energy Eng. 2002, 124, 109-125. [CrossRef]

19. Li, L.; Li, Y.S.; Sun, J. Prospective fully-coupled multi-level analytical methodology for concentrated solar power plants: applications. Appl. Therm. Eng. 2017, 118, 159-170. [CrossRef]

20. Li, L.; Sun, J.; Li, Y.S. Prospective fully-coupled multi-level analytical methodology for concentrated solar power plants: general modelling. Appl. Therm. Eng. 2017, 118, 171-187. [CrossRef]

21. Iodice, P.; Langella, G.; Amoresano, A. Optimization of medium temperature direct steam generation solar plant. Energy Procedia 2018, 148, 122-129. [CrossRef]

22. Laing, D.; Bahl, C.; Bauer, T.; Lehmann, D.; Steinmann, W.D. Thermal energy storage for direct steam generation. Sol. Energy 2011, 85, 627-633. [CrossRef]

23. Montes, M.; Rovira, A.; Muñoz, M.; Martínez-Val, J. Performance analysis of an integrated solar combined cycle using direct steam generation in parabolic trough collectors. Appl. Energy 2011, 88, 3228-3238.

24. Soteris Kalogirou, A. Solar thermal collectors and applications. Prog. Energy Combust Sci. 2004, 30, $231-295$. [CrossRef]

25. Winter, C.J.; Sizmann, R.L.; Vant-Hull, L.L. Solar Power Plants: Fundamentals, Technology, Systems, Economics; Springer: Berlin, Heidelberg, 1991.

26. Green, D.W. Perry's Chemical Engineering Handbook; McGrawHill Professional Publ.: New York, NY, USA, 2007.

27. Margolis, D.L. Analytical Modeling of Helical Screw Turbines for Performance Prediction. ASME J. Eng. Power 1978, 100, 482-487. [CrossRef]

28. Taniguchi, H.; Kudo, K.; Giedt, W.H.; Park, I.; Kumazawa, S. Analytical and Experimental Investigation of Two-Phase Flow Screw Expanders for Power Generation. ASME J. Eng. Gas Turbines Power 1988, 110, 628-635. [CrossRef]

29. Ng, K.C.; Bong, T.Y.; Lim, T.B. A thermodynamic model for the analysis of screw expander performance. Heat Recov. Syst CHP 1990, 10, 119-133. [CrossRef]

30. Wang, W.; Wu, Y.T.; Ma, C.F.; Xia, G.D.; Wang, J.F. Experimental study on the performance of single screw expanders by gap adjustment. Energy 2013, 62, 379-384. [CrossRef] 
31. Tang, H.; Wu, H.; Wang, X.; Xing, Z. Performance study of a twin-screw expander used in a geothermal organic Rankine cycle power generator. Energy 2015, 90, 631-642. [CrossRef]

32. Smith, I.K.; Stosic, N.; Mujic, E.; Kovacevic, A. Steam as the working fluid for power recovery from exhaust gases by means of screw expanders. Proc. Inst. Mech. Eng. Part E J. Process Mech. Eng. 2011, 225, 117-125. [CrossRef] 